\title{
Safely Stretching Our Options for Removing Large CBD Stones
}

\author{
R. Daniel Lawson • Thomas Savides
}

Published online: 2 March 2013

(c) Springer Science+Business Media New York 2013

In $10-15 \%$ of endoscopic retrograde cholangiopancreatography (ERCP) procedures performed for the indication of suspected choledocholithiasis, identified stones can be difficult to remove [1]. Common factors associated with failure include stones $>1 \mathrm{~cm}$, numerous stones, and altered biliary anatomy. There are several techniques for removing these "difficult CBD stones". Leaving a plastic biliary stent in place with or without ursodeoxycholic acid therapy with subsequent ERCP is often successful [2]. Mechanical lithotripsy (ML) fragmentation combined with biliary sphincterotomy (EST) successfully removes many large stones [3, 4]. Complications following biliary sphincterotomy and ML include bleeding, pancreatitis, and perforation and are usually mild and self-limited but on rare occasions can cause short-term morbidity or even death [5]. Electrohydraulic lithotripsy can be useful for disintegrating

R. Daniel Lawson: A military service member (or employee of the U.S. Government).

This work was prepared as part of my official duties. Title 17, USC, $\S 105$ provides that "Copyright protection under this title is not available for any work of the U.S. Government.' Title 17, USC, §101 defines a U.S. Government work as a work prepared by a military service member or employee of the U.S. Government as part of that person's official duties.

Disclaimer The views expressed in this presentation are those of the author and do not necessarily reflect the official policy or position of the Department of the Navy, Department of Defense, or the United States government.

R. D. Lawson · T. Savides $(\bowtie)$

Division of Gastroenterology, University of California,

San Diego, La Jolla, CA, USA

e-mail: tsavides@ucsd.edu

R. D. Lawson

e-mail: rlawson@ucsd.edu stones prior to removal, but requires direct visualization of the stone with cholangioscopy with attendant risks such as hemobilia, cholangitis, and ductal perforation [6].

Endoscopic papillary balloon dilation (EPBD), or balloon sphincteroplasty, has evolved as another technique for removing large bile duct stones. Controlled radial expansion (CRE) balloons $6-10 \mathrm{~mm}$ in diameter stretch the intact sphincter of Oddi to facilitate stone removal. Though early experience with balloon sphincteroplasty was promising, subsequent multicenter, randomized controlled trials reported overall higher rates of pancreatitis including severe pancreatitis leading to death in some patients treated with balloon sphincteroplasty [7, 8]. While balloon sphincteroplasty remains an accepted practice in some parts of the world, the American Society for Gastrointestinal Endoscopy only recommends EPBD for patients in whom sphincterotomy is considered too risky or difficult such as patients medically anticoagulated or those with post-surgical anatomy or a periampullary diverticulum [1].

Endoscopic papillary large-balloon dilation (EPLBD) is a technique introduced in 2003 that dilates with a 12 to 20-mm CRE balloon following biliary sphincterotomy [9]. Balloon size is chosen to be at least the same diameter as the stone but no larger than the diameter of the bile duct. The initial published retrospective series reported that biliary stones too large to be removed despite a complete sphincterotomy and use of an extraction balloon or basket could be successfully removed in most cases without the use of ML [9]. Furthermore, the overall complication rate was an acceptable $15.5 \%$, consisting of mild-to-moderate cholangitis, pancreatitis, and bleeding, with no deaths [9].

Several retrospective studies, prospective series, and randomized controlled studies have reported that EPLBD is an effective and mostly safe method for the removal of large CBD stones [10-16]. A recent systematic review of 
Table 1 Guidelines for performing safe EPLBD removal of challenging CBD stones

Do not perform EPLBD if there is distal CBD stricture

Limit length of endoscopic sphincterotomy to $<2 / 3$ of the length of ampulla immediately prior to large-balloon dilation to prevent perforation or bleeding

Inflate the balloon gradually until the "waist" disappears

Discontinue balloon inflation when resistance is encountered in the presence of a persistent balloon "waist" or if a "waist" persists in the balloon after inflation to $75 \%$ of the balloon manufacturer's maximum recommended balloon pressure

Do not inflate balloon beyond the maximal size of the upstream dilated CBD

Consider alternative stone removal methods such as mechanical lithotripsy, electrohydraulic lithotripsy, or placing a plastic stent when meeting any difficulty in removing stones via EPLBD

Modified from reference [18]

21 studies involving 1,292 patients who underwent treatment with EPLBD for choledocholithiasis revealed an overall successful clearance of the CBD in $98 \%$ of subjects with only $9.3 \%$ requiring ML [17]. The vast majority (91\%) could be completed during the initial ERCP. Adverse events (5\%) were mostly mild-to-moderate pancreatitis and bleeding, but also included cholecystitis, cholangitis, and duodenal and biliary perforation, similar to those reported for ML [3-5].

In the current issue of Digestive Diseases and Sciences, Park et al. [18] report a retrospective analysis of the largest dataset every compiled on the topic of EBPLD in order to evaluate performance characteristics of the procedure. They retrospectively collected data from 12 Japanese and Korean academic medical centers on 946 consecutive adult patients who had been treated with EPLBD or large-balloon sphincteroplasty in the treatment of $\geq 10 \mathrm{~mm}$ common bile duct (CBD) stones, in order to risk-stratify the population for the development of procedure-related adverse events. Most patients were treated with either a limited (44\% of patients, "Mid-EST". $<2 / 3$ ampulla length) or complete (23\%, "Full-EST", $>2 / 3$ ampulla length) sphincterotomy. The remaining $33 \%$ of patients were treated with sphincteroplasty alone ("No-EST"). Dilation was completed under endoscopic and fluoroscopic guidance using a 5.5-cm-long CRE balloon $12-20 \mathrm{~mm}$ in diameter to match the size of stone and/or bile duct diameter. Successful stone removal was achieved in $97 \%$ of the procedures with $21 \%$ requiring use of ML. The average stone size was $15.3 \mathrm{~mm}$. Adverse events occurred in 95 patients $(10 \%)$ comprising of bleeding $(6 \%)$, pancreatitis $(2.5 \%)$, biliary or duodenal perforation (1\%), and cholangitis $(0.6 \%)$. Most events were mild $(82 \%)$ or moderate $(13 \%)$ in severity; however, there were five cases with a severe adverse event (one hemorrhage and four perforations), four of which were fatal.

Multivariate analysis revealed four significant independent predictors of adverse events. Three variables, cirrhosis, full-EST, and stone size $\geq 16 \mathrm{~mm}$, were each associated with significantly higher risks of any adverse event or bleeding. The presence of a distal CBD stricture was associated with a 17-fold increased risk of perforation.

One patient died after severe bleeding occurred in the setting of thrombocytopenia $\left(84 \times 10^{3} / \mu \mathrm{l}\right)$ and a full sphincterotomy. The other three deaths occurred in patients who had a distal CBD stricture and had undergone a complete sphincterotomy. A distal CBD stricture was not always cholangiographically visualized prior to dilation. In some instances, the stricture became evident only during dilation, manifesting as either sustained resistance to balloon inflation or as a persistent fluoroscopically visualized "waist" in the balloon despite inflation of a $20-\mathrm{mm}$ balloon to $75 \%$ of the recommended maximal pressure.

The authors conclude by listing several guidelines for performing EPLBD as listed in Table 1. These recommendations provide excellent guidelines for practitioners to safely perform EPLBD. Additionally, the use of leaving a plastic stent in place (with or without ursodeoxycholic acid) and repeating ERCP at another time (and perhaps by a different endoscopist) is also worth considering. Practitioners should be aware that $10 \%$ of patients still required mechanical lithotripsy to remove the stones, and ideally ML should be available if attempting EPLBD. They should also inform their patients that on average it takes more than one ERCP session (average 1.4 ERCPs) to remove the stones.

There are still unanswered questions regarding optimal sphincterotomy length (or even the need for sphincterotomy), balloon size, the impact of prior endoscopic sphincterotomy, and subsequent recurrence rate of CBD stones. It is also unclear if the performance characteristics of EPLBD will be different in the community of general gastroenterologists with much lower ERCP volume. Future prospective studies might compare EPLBD directly with ML, EHL, plastic stents, and surgery to define the optimal approach.

In summary, EPLBD is now an accepted strategy in the treatment of challenging biliary stones, incorporated into several management algorithms [19,20]. Given the relative simplicity of this method that utilizes commonly available 
and familiar equipment, EPLBD is a very attractive alternative to mechanical lithotripsy, having the potential for widespread worldwide use. This study by Park et al. helps guide our patient selection and technique performance of EPLBD to optimize the safe and effective removal of challenging CBD stones.

\section{References}

1. ASGE Standards of Practice Committee, Maple JT, Ikenberry SO, et al. The role of endoscopy in the management of choledocholithiasis. Gastrointest Endosc. 2011;74:731-744.

2. Yang J, Peng JY, Chen W. Endoscopic biliary stenting for irretrievable common bile duct stones: indications, advantages, disadvantages, and follow-up results. Surg. 2012;10:211-217.

3. Garg PK, Tandon RK, Ahuja V, Makharia GK, Batra Y. Predictors of unsuccessful mechanical lithotripsy and endoscopic clearance of large bile duct stones. Gastrointest Endosc. 2004;59: 601-605.

4. Chang WH, Chu CH, Wang TE, Chen MJ, Lin CC. Outcome of simple use of mechanical lithotripsy of difficult common bile duct stones. World J Gastroenterol. 2005;11:593-596.

5. Thomas M, Howell DA, Carr-Locke D, et al. Mechanical lithotripsy of pancreatic and biliary stones: complications and available treatment options collected from expert centers. Am J Gastroenterol. 2007;102:1896-1902.

6. DiSario J, Chuttani R, Croffie J, et al. Biliary and pancreatic lithotripsy device. Gastrointest Endosc. 2007;65:750-756.

7. Freeman ML, DiSario JA, Nelson DB, et al. Risk factors for postERCP pancreatitis: a prospective, multicenter study. Gastrointest Endosc. 2001;54:425-434.

8. DiSario JA, Freeman ML, Bjorkman DJ, et al. Endoscopic balloon dilation compared with sphincterotomy for extraction of bile duct stones. Gastroenterology. 2004;127:1291-1299.

9. Ersoz G, Tekesin O, Ozutemiz AO, Gunsar F. Biliary sphincterotomy plus dilation with a large balloon for bile duct stones that are difficult to extract. Gastrointest Endosc. 2003;57:156-159.
10. Attasaranya S, Cheon YK, Vittal H, et al. Large-diameter biliary orifice balloon dilation to aid in endoscopic bile duct stone removal: a multicenter series. Gastrointest Endosc. 2008;67: 1046-1052.

11. Bang S, Kim MH, Park JY, Park SW, Song SY, Chung JB. Endoscopic papillary balloon dilation with large balloon after limited sphincterotomy for retrieval of choledocholithiasis. Yonsei Med J. 2006;47:805-810.

12. Minami A, Hirose S, Nomoto T, Hayakawa S. Small sphincterotomy combined with papillary dilation with large balloon permits retrieval of large stones without mechanical lithotripsy. World J Gastroenterol. 2007;13:2179-2182.

13. Garcia-Cano J, Arana LT, Ayllon CJ, et al. Biliary sphincterotomy dilation for the extraction of difficult common bile duct stones. Revista Espanola de Enfermedades Digestivas. 2009;101: 541-545.

14. Maydeo A, Bhandar IS. Balloon sphincteroplasty for removing difficult bile duct stones. Endoscopy. 2007;39:958-961.

15. Heo JH, Kang DH, Jung HJ, et al. Endoscopic sphincterotomy plus large-balloon dilation versus endoscopic sphincterotomy for removal of bile-duct stones. Gastrointest Endosc. 2007;66: 720-726.

16. Teoh AY, Cheung FK, Hu B, et al. Randomized trial of endoscopic sphincterotomy with balloon dilation versus endoscopic sphincterotomy alone for removal of bile duct stones. Gastroenterology. 2013;144:341-345.

17. Meine GC, Baron TH. Endoscopic papillary large-balloon dilation combined with endoscopic biliary sphincterotomy for the removal of bile duct stones (with video). Gastrointest Endosc. 2011;74:1119-1126.

18. Park SJ, Kim JH, Hwang JC, et al. Factors predictive of adverse events following endoscopic papillary large balloon dilation: results from a multicenter series. Dig Dis Sci. 2012. (Epub ahead of print). doi: 10.1007/s10620-012-2494-8.

19. Stefanidis G, Christodoulou C, Manolakopoulos S, Chuttani R. Endoscopic extraction of large common bile duct stones: a review article. World J Gastrointest Endosc. 2012;4:167-179.

20. Yoo KS, Lehman GA. Endoscopic management of biliary ductal stones. Gastro Clin N Am. 2010;39:209-227. 